\title{
Voxel-based asymmetry of the regional gray matter over the inferior temporal gyrus correlates with depressive symptoms in medicated patients with major depressive disorder
}

\author{
Krisztián Kocsis $^{\mathrm{a}, 1}$, Adrienn Holczer ${ }^{\mathrm{a}, 1}$, Csaba Kazinczi ${ }^{\mathrm{a}}$, Katalin Boross ${ }^{\mathrm{b}}$, Regina Horváth ${ }^{\mathrm{b}}$, \\ Luca Viola Németh $^{\mathrm{a}}$, Péter Klivényi ${ }^{\mathrm{a}}$, Zsigmond Tamás Kincses ${ }^{\mathrm{b}}$, Anita Must ${ }^{\text {c, }}$ \\ ${ }^{a}$ Department of Neurology, Albert Szent-Györgyi Health Centre, University of Szeged, Hungary \\ ${ }^{\mathrm{b}}$ Department of Radiology, Albert Szent-Györgyi Health Centre, University of Szeged, Hungary \\ ${ }^{\mathrm{c}}$ Institute of Psychology, Faculty of Arts, University of Szeged, Egyetem utca 2 H-6722, Szeged, Hungary
}

\section{A R T I C L E I N F O}

\section{Keywords:}

Major depressive disorder

Gray matter asymmetry

Inferior temporal gyrus

Depression severity

\begin{abstract}
A B S T R A C T
The number of patients suffering from major depressive disorder (MDD) is increasing worldwide. Imbalanced hemispherical brain activity may be an underlying factor of MDD; however, whether structural asymmetry also contributes to the symptoms experienced in MDD has been scarcely investigated. In this study, we aimed to examine cortical asymmetry in association with the severity of depressive and cognitive symptoms observed in MDD during stable medication. The association between the affective and cognitive symptoms and gray matter asymmetry was evaluated in 17 MDD patients using voxel-wise gray matter asymmetry analysis on highresolution T1-weighted MR images. Asymmetry index values in the inferior temporal gyrus (ITG) correlated with the scores of the 17-item Hamilton Depression Rating Scale (HDRS), but no association was found with the Beck Hopelessness Scale, and performance on the 1-, 2- and 3-back task. Our results indicate that the asymmetry of gray matter content in the ITG might be associated with higher depression severity. Our findings might help to better understand how structural changes contribute to depression severity in patients with MDD.
\end{abstract}

\section{Introduction}

Major depressive disorder (MDD) is a debilitating condition affecting mood, cognition, sleep, appetite, and libido (Kennedy 2008). The regulation of these functions involves several brain areas as well as brain circuitries, and consequently, structural abnormalities and functional disruptions have been reported across the entire brain in MDD (Drevets et al., 2008; Suh et al., 2020; Ye et al., 2016). The frontal areas have been implied to show imbalanced brain activity and metabolism with right hemispheric hyperactivity compared to the relative hypoactivity of the left side (for a review see Hecht, 2010). The presence of imbalance has also been supported by EEG (electroencephalography) measures in the alpha frequency range (Grunewald et al., 2018). Moreover, frontal alpha asymmetry seems to correlate with depressive symptoms including symptom severity, psychomotor retardation, and suicidal behavior (Cantisani et al., 2015; Diego et al., 2001; Park et al., 2019). Whether gray matter structural asymmetries are also present in MDD has only been investigated directly in four studies (see Table 1 for a summary), suggesting abnormal frontal and temporal asymmetries (Kumar et al., 2000; Liu et al., 2016; Zuo et al., 2019) or unilateral volume differences compared to healthy controls (Schmaal et al., 2017; van Tol et al., 2014).

A recent large-scale asymmetry analysis conducted by the ENIGMA Consortium comparing gyral-based regions of interest (ROIs), however, has not supported the presence of any cortical asymmetries as compared to healthy participants (de Kovel et al., 2019; Kong et al., 2020). Although this study has high statistical power and sample size, its results do not exclude the possibility that subregions within the examined ROIs and/or subgroups of MDD patients show structural asymmetry that might contribute to the clinical (either cognitive or affective) manifestations of MDD. Convergence of asymmetric cortical volumes has been suggested when analyzing clinical subgroups of patients (distinguished based on medication status or the presence of comorbid disorders) (Gray et al., 2020). Furthermore, voxel-based analyses may be performed to test if certain gray matter subregions (instead of predefined

\footnotetext{
* Corresponding author.

E-mail address: must.anita@med.u-szeged.hu (A. Must).

1 These authors contributed equally to this work
} 
ROIs) show abnormal asymmetry.

Structural asymmetries in MDD have been linked to depressive symptoms, indicating their potential relevance in the pathomechanism of MDD. For instance, higher structural asymmetry of the dorsolateral prefrontal cortex (DLPFC) correlated with self-reported depressive symptoms in subclinical and major depression (Liu et al., 2016). Strikingly, associations between structural asymmetry and other core aspects of MDD (e.g., cognitive symptoms or suicidal ideations) have not been explored previously, despite cognitive deficit being a prominent feature of MDD (Gärtner et al., 2018; Mohn and Rund, 2016).

In the present study, we aimed to investigate voxel-based cortical asymmetry in association with the severity of both depressive and cognitive symptoms observed in MDD patients with stable medication status. The interaction of voxel-based asymmetry with depressive symptoms, hopelessness, attention, and working memory were examined to identify brain areas with abnormal cortical asymmetry linked to potential residual symptoms. The voxel-based approach we are using in the current investigation provides higher spatial resolution and does not suffer from the inherent bias of ROI-based methods (Astrakas and Argyropoulou 2010). A protocol for voxel-wise gray matter asymmetry calculation was performed to investigate the association between cortical asymmetries and the cognitive symptoms and MDD severity (Kurth et al., 2015).

\section{Methods}

\subsection{Participants}

Seventeen patients with MDD diagnosed by expert clinicians were recruited from the Department of Psychiatry of the Albert Szent-Györgyi Health center, University of Szeged (see Table 2 for sample characteristics). The medication status of all patients was kept stable at least two weeks prior to the neuroimaging recordings. Antidepressant treatment was combined with benzodiazepines in the case of 8 participants, 4 patients received antidepressants only, and 5 participants took benzodiazepines without antidepressant medication. The antidepressants were classified as follows: serotonin and norepinephrine reuptake inhibitors $(n=4)$, selective serotonin reuptake inhibitors $(n=2)$, atypical antidepressants $(n=2)$, tetracyclic antidepressants $(n=2)$, monoamine oxidase inhibitor $(n=1)$, and tricyclic antidepressant $(n=1)$. The study was approved by the Ethics Committee of the University of Szeged (Ref. No.: 165/2014). All participants gave written informed consent in
Table 2

Sample characteristics.

\begin{tabular}{lll}
\hline Age (years, mean \pm SD) & $49.78 \pm 13.12$ \\
HDRS score (mean \pm SD) & $17.58 \pm 5.64$ \\
\hline \multirow{2}{*}{ Sex } & Male & 3 \\
\multirow{3}{*}{ Education level } & Female & 14 \\
& Primary & 2 \\
& Secondary & 9 \\
& Vocational education & 2 \\
& University & 4 \\
Medication status & Antidepressant only & 4 \\
& Benzodiazepine only & 2 \\
& Antidepressant and benzodiazepine & 11 \\
& combined & \\
\hline
\end{tabular}

accordance with the Declaration of Helsinki.

\subsection{Assessment of affective and cognitive symptoms}

To assess depression-related symptoms, a half-structured interview, the 17-item HDRS was administered. The HDRS comprises the assessment of several symptoms including affective state, suicidal thoughts, somatic symptoms, sleeping and eating behavior, and sexual symptoms (Hamilton, 1986). The HDRS is a frequently used tool in clinical research (Behera et al., 2017). The short, 4-item version of the Beck Hopelessness Scale (BHS) was also administered to further explore negative expectations and hopelessness (Beck and Steer, 1988).

Three levels of the n-back task (1-back, 2-back, and 3-back) were performed in ascending order by each participant. The task was presented using PsychoPy (version: v1.82.01). Stimuli selected from a set of capital letters (A, C, E, I, K, L, S, O, R, T, U) were presented consecutively on the screen for $1500 \mathrm{~ms}$ with 500-ms-long interstimulus intervals. During the 1-back task, participants were asked to press the spacebar if the target stimulus presented on the screen was the same as the previous one. During the 2-back and 3-back tasks, the spacebar had to be pressed if the second or third letter preceding the target stimulus was identical with the letter presented, respectively. At each level, a total of 100 trials were completed, and $20 \%$ of all presented stimuli were target stimuli to which participants were expected to respond. Sensitivity index ( $d$ ' score) was calculated for all levels based on the signal detection theory by subtracting the false alarm rate from the hit rate, both expressed in zscores: $d^{\prime}=Z$ (hit rate) $Z$ (false alarm rate) (Haatveit et al., 2010). $d^{\prime}$ scores of the 1-back task were interpreted in the attention domain, while

Table 1

\begin{tabular}{|c|c|c|c|c|c|c|c|}
\hline Study & $\begin{array}{l}\text { Sample } \\
\text { Patient } \\
\text { characteristics }\end{array}$ & Medication status & $\begin{array}{l}\text { Methods } \\
\text { Methods, examined } \\
\text { regions }\end{array}$ & $\begin{array}{l}\text { Asymmetry } \\
\text { index }\end{array}$ & $\begin{array}{l}\text { Results } \\
\text { Correlation with } \\
\text { symptoms }\end{array}$ & Asymmetry compared to HCs & $\begin{array}{l}\text { Direction of } \\
\text { asymmetry }\end{array}$ \\
\hline $\begin{array}{l}\text { Zuo } \\
\text { et al. } \\
\text { (2019) }\end{array}$ & First-episode MDD & $\begin{array}{l}\text { Treatment-naïve } \\
\text { patients }\end{array}$ & Cortical thickness & $\begin{array}{l}\mathrm{AI}=(\mathrm{L}-\mathrm{R}) \times \\
100 /(L+R)\end{array}$ & $\begin{array}{l}\text { No correlation } \\
\text { between } \\
\text { symptom severity } \\
\text { and AIs }\end{array}$ & $\begin{array}{l}\text { Higher AI in the caudal } \\
\text { middle frontal cortex, } \\
\text { superior frontal cortex and } \\
\text { rostral middle frontal cortex } \\
\text { in MDD }\end{array}$ & $\begin{array}{l}\text { left- } \\
\text { lateralization }\end{array}$ \\
\hline $\begin{array}{l}\text { Kumar } \\
\text { et al. } \\
\text { (2000) }\end{array}$ & $\begin{array}{l}\text { Late-onset MDD or } \\
\text { late-onset minor } \\
\text { depression }\end{array}$ & $\mathrm{N} / \mathrm{R}$ & $\begin{array}{l}\text { Volume of the cerebral } \\
\text { hemispheres, frontal and } \\
\text { temporal lobes }\end{array}$ & $\begin{array}{l}\mathrm{AI}=(\mathrm{R}-\mathrm{L}) / \\
(L+R) \times 100\end{array}$ & N/A & $\begin{array}{l}\text { Smaller left-right frontal AI } \\
\text { in minor depression and } \\
\text { MDD }\end{array}$ & $\begin{array}{l}\text { less right- } \\
\text { lateralized }\end{array}$ \\
\hline $\begin{array}{r}\text { Liu et al. } \\
(2016)\end{array}$ & $\begin{array}{l}\text { First-episode MDD } \\
\text { + responders to } \\
\text { antidepressant } \\
\text { medication }\end{array}$ & $\begin{array}{l}\text { Treatment-naïve } \\
\text { patients + patients } \\
\text { receiving } \\
\text { antidepressant } \\
\text { medication }\end{array}$ & $\begin{array}{l}\text { ROI analysis: } \\
\text { asymmetry indexes of the } \\
\text { DLPFC, hippocampus, } \\
\text { amygdala, insula, PFC } \\
\text { and the whole brain }\end{array}$ & $\mathrm{AI}=R-\mathrm{L}$ & $\begin{array}{l}\text { DLPFC AI } \\
\text { negatively } \\
\text { correlated with } \\
\text { self-reported } \\
\text { depression }\end{array}$ & $\begin{array}{l}\text { Lower asymmetry index in } \\
\text { first-episode, treatment- } \\
\text { naïve MDD patients (also in } \\
\text { individuals with subclinical } \\
\text { depression) } \\
\text { Antidepressants normalized } \\
\text { AI abnormalities in } \\
\text { medicated MDD patients }\end{array}$ & $\begin{array}{l}\text { less right- } \\
\text { lateralized }\end{array}$ \\
\hline $\begin{array}{l}\text { de Kovel } \\
\text { et al. } \\
\text { (2019) }\end{array}$ & $\begin{array}{l}\text { First-episode }+ \\
\text { recurrent MDD (in } \\
\text { an acute or remitted } \\
\text { state) }\end{array}$ & $\begin{array}{l}\text { Treatment-naïve }+ \\
\text { patients receiving } \\
\text { antidepressant } \\
\text { medication }\end{array}$ & $\begin{array}{l}\text { ROI analysis: thickness } \\
\text { and surface area } \\
\text { measures for each of } 34 \\
\text { bilaterally paired cortical } \\
\text { regions }\end{array}$ & $\begin{array}{l}\mathrm{AI}=(\mathrm{L}-\mathrm{R}) / \\
(L+R)\end{array}$ & N/A & $\begin{array}{l}\text { Higher superior temporal } \\
\text { gyrus thickness AI in MDD } \\
\text { (not statistically significant } \\
\text { after correction for multiple } \\
\text { comparison) }\end{array}$ & $\begin{array}{l}\text { right- } \\
\text { lateralization }\end{array}$ \\
\hline
\end{tabular}


the results of the 2-back and 3-back tasks were interpreted in the working memory domain (Martin et al., 2016).

\subsection{Data acquisition}

Magnetic resonance imaging (MRI) was performed using a $1.5 \mathrm{~T} \mathrm{GE}$ Signa Excite HDxt MR Scanner (GE Healthcare, Chalfont St. Giles, UK). Three-dimensional high-resolution T1-weighted anatomical images were acquired for all participants (3D spoiled gradient echo images with inversion recovery (3D FSPGR IR): echo time [TE]: $4.1 \mathrm{~ms}$; repetition time [TR]: $10.276 \mathrm{~ms}$; matrix: $256 \times 256$, field of view [FOV]: $25 \times 25$ $\mathrm{cm}$, flip angle: $15^{\circ}$, in-plane resolution: $1 \times 1 \mathrm{~mm}$, slice thickness: 1 $\mathrm{mm})$.

\subsection{Data analysis}

The image analysis was carried out using the VBM8 Toolbox (http:// www.neuro.uni-jena.de/vbm/download/) implemented in Statistical Parametric Mapping 8 (SPM8; Wellcome Trust center for Neuroimaging, London, UK) software (https://www.fil.ion.ucl.ac.uk/spm/softw are/spm8/). In order to create a symmetric gray matter skeleton containing gray matter asymmetry index (AI) values for each voxel, a stepby-step guideline published by Kurth and colleagues was followed (Kurth et al., 2015). All non-brain parts were removed from the T1-weighted images and then the brain was segmented into gray matter, white matter, and cerebrospinal fluid. All gray and white matter segments were flipped along the midline prior to creating the symmetric Diffeomorphic Anatomical Registration using Exponentiated Lie Algebra (DARTEL) template from the original and flipped gray and white matter segments (Ashburner 2007). Afterwards, the images were registered to the mean DARTEL template and averaged, and a binarized right hemisphere mask was created in the symmetric template space to limit statistical calculations to the right hemisphere. Then, we calculated an asymmetry index based on the following equation:

$A I=\left(\frac{(i 1-i 2) .}{(i 1+i 2) \cdot * 0.5}\right) * i 3$

where (i1) = warped original gray matter segment; $(i 2)=$ warped flipped gray matter segment and $(i 3)=$ binarized right-hemisphere mask image. Positive AI values indicate more gray matter in the right hemisphere (rightward asymmetry), while negative AI value means higher gray matter content in the left hemisphere (leftward asymmetry). After image pre-processing, all AI images were spatially smoothed using an 8 $\mathrm{mm}$ smoothing kernel. Finally, a voxel-wise general linear model (GLM) as implemented in the FMRIB Software Library (https://fsl.fmrib.ox.ac. $\mathrm{uk} / \mathrm{fsl} / \mathrm{fs} l w i k i / G L M)$ was performed. Age and sex served as covariates, while positive and negative contrasts were calculated for HDRS, BHS, and $d$ ' scores to test bidirectional associations with the AI values. Then, permutation-based non-parametric testing was performed with a thresholding using threshold-free cluster enhancement technique. The images were thresholded at $p<0.05$ and corrected for multiple comparisons with a family-wise error rate (FWE) correction. The design matrices contained the age, sex, and HDRS, BHS and $d$ ' scores for each subject separately.

\section{Results}

The result of voxel-based gray matter asymmetry analysis was visualized as an overlay on the MNI152 $2 \mathrm{~mm}$ standard brain. Gray matter asymmetry analysis yielded a significant negative correlation between the gray matter AI values of the inferior temporal gyrus (ITG) and the individual HDRS scores (Fig. 1), as determined by the MNI152 standard space coordinates $(x=18, y=55, z=17)$. No significant association was found between the gray matter AI values and the BHS and $d$ ' scores derived from n-back task.

The higher the HDRS scores, the lower or more negative the AI values were, as indicated by the AI values extracted from the significant cluster ( $R=-0.879, p \leq 0.001$ ) (Fig. 2). Thus, in patients with more severe depressive symptoms, a higher leftward asymmetry in the ITG (i.e., lower gray matter content in the right hemisphere, higher gray matter content in the left hemisphere) can be observed.

\section{Discussion}

Brain abnormalities in MDD have been widely investigated to better understand the neural background of this debilitating disorder. The aim of the present study was to examine the association of affective and cognitive symptoms with cortical asymmetries in MDD patients under stable medication. Voxel-based cortical asymmetry calculations were carried out indicating a leftward asymmetry within the ITG in patients with more severe depressive symptoms (i.e., the higher the depression severity, the less gray matter volume in the right ITG as compared to the left homologue area). No similar association or any asymmetry within other brain regions was found with respect to hopelessness and cognitive measures. While previous ROI-based studies have reported no abnormal asymmetry or results limited to specific MDD subgroups (de Kovel et al., 2019; Kong et al., 2020), our analysis showed a cluster of voxel-wise asymmetries within the ITG that were in association with depressive symptoms present in medicated MDD patients. Such small changes might be overlooked if imaging data is analyzed using predefined ROIs.

The ITG has previously been reported to show an asymmetric reduction of gray matter volume (Schmaal et al., 2017), especially in medication naïve (Guo et al., 2014a; Gray et al., 2020) and first-episode

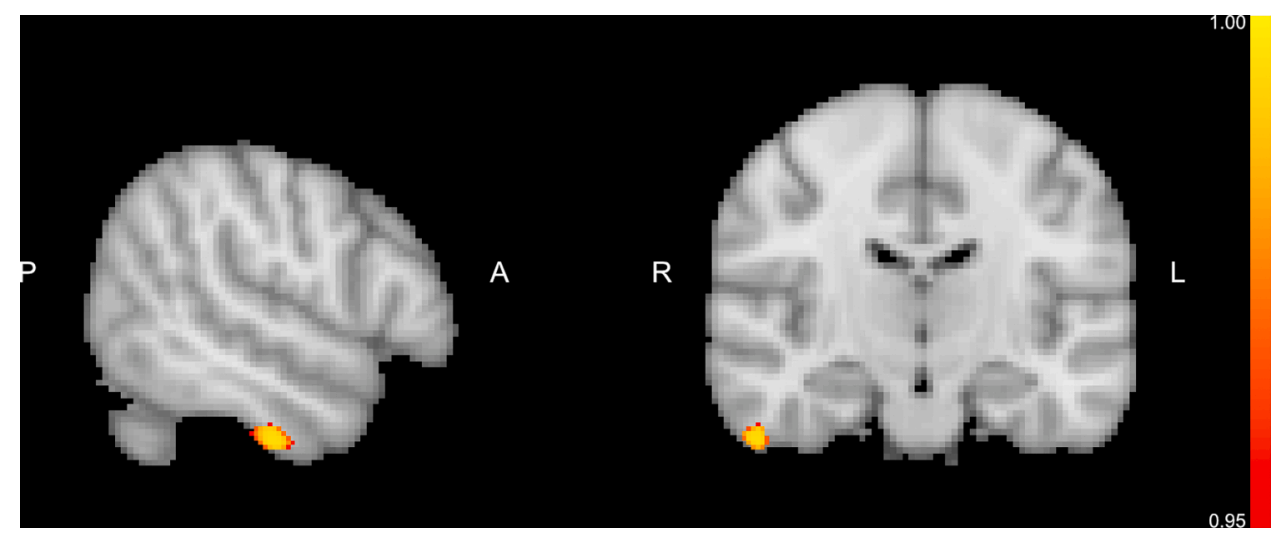

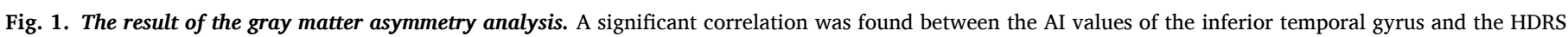

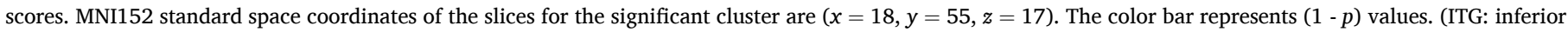
temporal gyrus, HDRS: Hamilton Depression Rating Scale). 


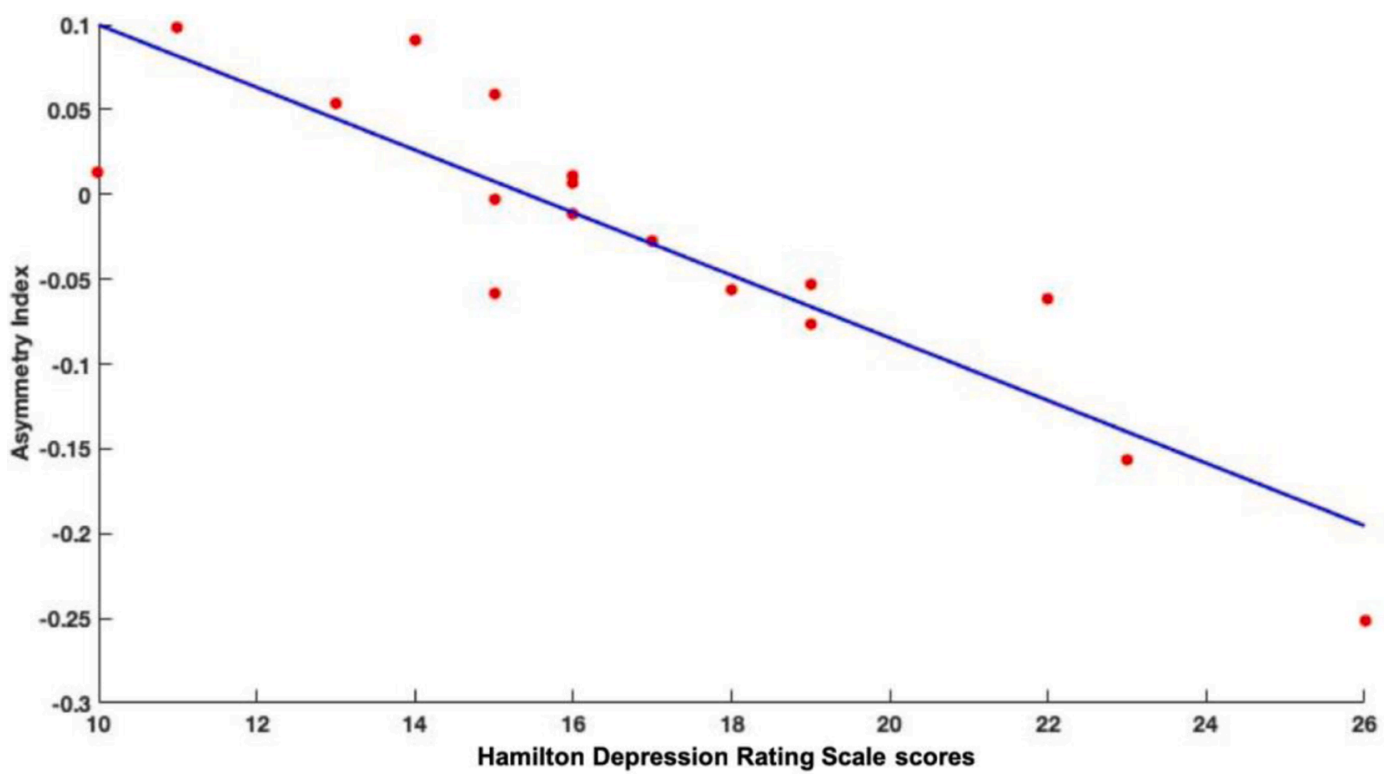

Fig. 2. Correlation between the AI values of ITG and the HDRS scores. (ITG: inferior temporal gyrus, HDRS: Hamilton Depression Rating Scale).

MDD patients (Peng et al., 2011). Moreover, the volume of the ITG has had a positive correlation with the 17-item HDRS scores and with longer reaction times on an attention task (Li et al., 2010). The ITG has also been found to be affected in other disorders, such as schizophrenia (Onitsuka et al., 2004) and bipolar affective disorder (Gong et al., 2019). Summarizing all these results, the ITG appears to be affected in several disorders including MDD, which casts light on its potential importance in the pathomechanism of these conditions.

The ITG seems to be engaged in cognitive processes such as semantic processing and concept retrieval (Faber et al., 2014), but also contributes to social cognition (Gallagher and Frith, 2003), self-referential processing (Herold et al., 2016) and the processing of affective stimuli (Hu et al., 2017). On a network-level, the ITG seems to be involved in the extended default mode network (DMN) (Allen and Williams 2011; Guo et al., 2014b), which is reported to show an imbalance in MDD (Hamilton et al., 2015). More specifically, an abnormally decreased network homogeneity (Guo et al., 2014b) and reduced amplitude of low-frequency fluctuation (indicating the absolute intensity of spontaneous brain activity) of the right ITG has been observed within the DMN as compared to healthy individuals (Guo et al., 2014b). Our results linking the structural features of the ITG to the clinical symptoms of depression supplement the findings on functional disruptions and suggest that the gray matter content of the ITG might contribute to a larger-scale network-level abnormality relating to negative affect and rumination.

In light of these results, the characteristics of the ITG in MDD should be explored more thoroughly, such as the extent of its white matter network and its relationship with functional or behavioral factors associated with depression. Furthermore, ITG may be suitable as a target for non-invasive brain stimulation (e.g., transcranial magnetic stimulation, transcranial electrical stimulation). These interventions have been utilized to mitigate the affective and cognitive symptoms in MDD (Iimori et al., 2019; Holczer et al., 2021) and to supplement the effects of the ongoing medication (Berlim et al., 2013; Plewnia et al., 2014). By stimulating the ITG, the residual symptoms might be further mitigated; however, this requires empirical support.

Limitations of the present study include sample size and imbalanced sex ratio. However, we corrected for the effects of sex and age by performing a covariate analysis. From the present study, we cannot clearly determine if and which pharmaceutical preparation has an effect on the structural changes of the ITG. In our sample, different types of medication (e.g., selective serotonin reuptake inhibitors, serotonin and norepinephrine reuptake inhibitors) were administered to the patients. Thus, future longitudinal-design studies should explore the antidepressant effects on the gray matter volume of the ITG.

An additional limitation may be the validity of HDRS-17 among patients undergoing different drug therapies as different therapies may induce divergent responses in terms of the final score and its subcomponents. It would be necessary to take additional samples assessed with another psychometric tool measuring depression (e.g., the Beck Depression Inventory). However, antidepressants regardless of the exact type seem to decrease depressive symptoms, and their network-level effect mainly acts on the connection strength between symptomdomains (Berlim et al., 2020). Since our results are cross-sectional, longitudinal studies are needed to examine whether depression severity is consistently associated with the structural changes of the ITG.

\section{Conclusion}

In the present study, we examined the association of affective and cognitive symptoms with cortical asymmetries in medicated MDD patients and found that the leftward shift of the ITG was associated with higher depression severity. The understanding of cerebral pathology is essential and may facilitate more targeted approaches for the prevention and management of MDD.

\section{CRediT authorship contribution statement}

Krisztián Kocsis: Data curation, Formal analysis, Writing - original draft, Writing - review \& editing. Adrienn Holczer: Data curation, Writing - original draft, Writing - review \& editing. Csaba Kazinczi: Data curation, Writing - original draft. Katalin Boross: Data curation, Formal analysis. Regina Horváth: Data curation, Formal analysis. Luca Viola Németh: Data curation, Formal analysis. Péter Klivényi: Conceptualization, Writing - review \& editing. Zsigmond Tamás Kincses: Conceptualization, Writing - review \& editing. Anita Must: Conceptualization, Writing - review \& editing.

\section{Declaration of Competing Interest}

The authors declare no conflict of interest. 


\section{References}

Allen, M., Williams, G., 2011. Consciousness, plasticity, and connectomics: the role of intersubjectivity in human cognition. Front. Psychol. 2, 20.

Ashburner, J., 2007. A fast diffeomorphic image registration algorithm. Neuroimage 38 (1), 95-113.

Astrakas, L.G., Argyropoulou, M.I., 2010. Shifting from region of interest (ROI) to voxelbased analysis in human brain mapping. Pediatr. Radiol. 40 (12), 1857-1867.

Berlim, M.T., Van den Eynde, F., Daskalakis, Z.J., 2013. High-frequency repetitive transcranial magnetic stimulation accelerates and enhances the clinical response to antidepressants in major depression: a meta-analysis of randomized, double-blind, and sham-controlled trials. J. Clin. Psychiatry. 74 (2), e122-e129.

Beck, A.T., Steer, R.A., 1988. BHS, Beck hopelessness scale: manual. Psychological Corp. ; Harcourt Brace Jovanovich, San Antonio, Tex.; New York

Behera, P., Gupta, S.K., Nongkynrih, B., Kant, S., Mishra, A.K., Sharan, P., 2017. Screening instruments for assessment of depression. Indian J. Med. Spec. 8, 31-37. https://doi.org/10.1016/j.injms.2016.11.003.

Berlim, M.T., Richard-Devantoy, S., dos Santos, N.R., Turecki, G., 2020. The network structure of core depressive symptom-domains in major depressive disorder following antidepressant treatment: a randomized clinical trial. Psychol. Med. 1-15. 10.1017/S0033291720001002.

Cantisani, A., Koenig, T., Horn, H., Müller, T., Strik, W., Walther, S., 2015. Psychomotor retardation is linked to frontal alpha asymmetry in major depression. J. Affect. Disord. 188, 167-172. https://doi.org/10.1016/j.jad.2015.08.018.

de Kovel, C.G.F., Aftanas, L., Aleman, A., Alexander-Bloch, A.F., Baune, B.T., Brack, I., Bülow, R., Busatto Filho, G., Carballedo, A., Connolly, C.G., Cullen, K.R., Dannlowski, U., Davey, C.G., Dima, D., Dohm, K., Erwin-Grabner, T., Frodl, T., Fu, C. H.Y., Hall, G.B., Glahn, D.C., Godlewska, B., Gotlib, I.H., Goya-Maldonado, R., Grabe, H.J., Groenewold, N.A., Grotegerd, D., Gruber, O., Harris, M.A., Harrison, B. J., Hatton, S.N., Hickie, I.B., Ho, T.C., Jahanshad, N., Kircher, T., Krämer, B., Krug, A., Lagopoulos, J., Leehr, E.J., Li, M., MacMaster, F.P., MacQueen, G., McIntosh, A.M., McLellan, Q., Medland, S.E., Mueller, B.A., Nenadic, I., Osipov, E., Papmeyer, M., Portella, M.J., Reneman, L., Rosa, P.G.P., Sacchet, M.D., Schnell, K., Schrantee, A., Sim, K., Simulionyte, E., Sindermann, L., Singh, A., Stein, D.J., Ubani, B.N., Van der Wee, N.J.A., Van der Werff, S.J.A., Veer, I.M., VivesGilabert, Y., Völzke, H., Walter, H., Walter, M., Schreiner, M.W., Whalley, H., Winter, N., Wittfeld, K., Yang, T.T., Yüksel, D., Zaremba, D., Thompson, P.M., Veltman, D.J., Schmaal, L., Francks, C., 2019. No alterations of brain structural asymmetry in major depressive disorder: an ENIGMA consortium analysis. Am. J. Psychiatry 176, 1039-1049. https://doi.org/10.1176/appi.ajp.2019.18101144.

Diego, M.A., Field, T., Hernandez-Reif, M., 2001. CES-D depression scores are correlated with frontal EEG alpha asymmetry. Depress. Anxiety 13, 32-37 https://doi.org/ 10.1002/1520-6394(2001)13:1<32::AID-DA5>3.0.CO;2-G.

Drevets, W.C., Price, J.L., Furey, M.L., 2008. Brain structural and functional abnormalities in mood disorders: implications for neurocircuitry models of depression. Brain Struct. Funct. 213 (1-2), 93-118.

Faber, P., Verdejo, J., Leon, P., Reimerink, A., Guzman, G., 2014. Neural substrates of specialized knowledge representation: an fMRI study. Revue Francaise De Linguistique Appliquee 19 (1), 15-32.

Gallagher, H.L., Frith, C.D., 2003. Functional imaging of 'theory of mind.' . Trends Cogn. Sci. 7, 77-83. https://doi.org/10.1016/S1364-6613(02)00025-6.

Gärtner, M., Ghisu, M.E., Scheidegger, M., Bönke, L., Fan, Y., Stippl, A., HerreraMelendez, A.-.L., Metz, S., Winnebeck, E., Fissler, M., Henning, A., Bajbouj, M., Borgwardt, K., Barnhofer, T., Grimm, S., 2018. Aberrant working memory processing in major depression: evidence from multivoxel pattern classification. Neuropsychopharmacology 43, 1972-1979. https://doi.org/10.1038/s41386-0180081-1.

Gong, J.Y., Chen, G.M., Jia, Y.B., Zhong, S.M., Zhao, L.P., Luo, X.M., Qiu, S.J., Lai, S.K. Qi, Z.Z., Huang, L., Wang, Y., 2019. Disrupted functional connectivity within the default mode network and salience network in unmedicated bipolar II disorder. Prog. Neuropsychopharmacol. Biol. Psychiatry 88, 11-18.

Gray, J.P., Muller, V.I., Eickhoff, S.B., Fox, P.T., 2020. Multimodal abnormalities of brain structure and function in major depressive disorder: a meta-analysis of neuroimaging studies. Am. J. Psychiatry 177 (5), 422-434.

Grunewald, B.D., Greimel, E., Trinkl, M., Bartling, J., Grossheinrich, N., SchulteKorne, G., 2018. Resting frontal EEG asymmetry patterns in adolescents with and without major depression. Biol. Psychol. 132, 212-216.

Guo, W., Liu, F., Yu, M., Zhang, J., Zhang, Z., Liu, J., Xiao, C., Zhao, J., 2014a. Functional and anatomical brain deficits in drug-naive major depressive disorder. Prog. Neuropsychopharmacol Biol. Psychiatry 54, 1-6.

Guo, W., Liu, F., Zhang, J., Zhang, Z., Yu, L., Liu, J., Chen, H., Xiao, C., 2014b. Abnormal default-mode network homogeneity in first-episode, drug-naive major depressive disorder. PLoS ONE 9 (3), e91102.

Haatveit, B.C., Sundet, K., Hugdahl, K., Ueland, T., Melle, I., Andreassen, O.A., 2010. The validity of d prime as a working memory index: results from the "bergen n-back task". J. Clin. Exp. Neuropsychol. 32 (8), 871-880.

Hamilton, J.P., Farmer, M., Fogelman, P., Gotlib, I.H., 2015. Depressive rumination, the default-mode network, and the dark matter of clinical neuroscience. Biol. Psychiatry 78 (4), 224-230.

Hecht, D., 2010. Depression and the hyperactive right-hemisphere. Neurosci. Res. 68 (2), 77-87.

Herold, D., Spengler, S., Sajonz, B., Usnich, T., Bermpohl, F., 2016. Common and distinct networks for self-referential and social stimulus processing in the human brain. Brain Struct. Funct. 221 (7), 3475-3485.
Holczer, A.N., V.L.; Vékony, T.; Kocsis, K.; Király, A.; Kincses, Z.T.; Vécsei, L.; Klivényi, P.; Must, A. (2021). "The effects of bilateral theta-burst stimulation on executive functions and affective symptoms in major depressive disorder." Neuroscience.

Hu, B., Rao, J., Li, X.W., Cao, T., Li, J.X., Majoe, D., Gutknecht, J., 2017. Emotion regulating attentional control abnormalities in major depressive disorder: an eventrelated potential study. Sci. Rep. 7.

Iimori, T., Nakajima, S., Miyazaki, T., Tarumi, R., Ogyu, K., Wada, M., Tsugawa, S., Masuda, F., Daskalakis, Z.J., Blumberger, D.M., Mimura, M., Noda, Y., 2019. Effectiveness of the prefrontal repetitive transcranial magnetic stimulation on cognitive profiles in depression, schizophrenia, and Alzheimer's disease: a systematic review. Prog. Neuropsychopharmacol Biol. Psychiatry 88, 31-40.

Kennedy, S.H., 2008. Core symptoms of major depressive disorder: relevance to diagnosis and treatment. Dialogues Clin. Neurosci. 10 (3), 271-277.

Kong, X.-.Z., Postema, M.C., Guadalupe, T., Kovel, C.de, Boedhoe, P.S.W., Hoogman, M., Mathias, S.R., Rooij, D.van, Schijven, D., Glahn, D.C., Medland, S.E., Jahanshad, N., Thomopoulos, S.I., Turner, J.A., Buitelaar, J., Erp, T.G.M.van, Franke, B., Fisher, S. E., Heuvel, O.A.Van Den, Schmaal, L., Thompson, P.M., Francks, C., 2020. Mapping brain asymmetry in health and disease through the ENIGMA consortium. Hum. Brain Mapp. n/a. 10.1002/hbm.25033.

Kurth, F., Gaser, C., Luders, E., 2015. A 12-step user guide for analyzing voxel-wise gray matter asymmetries in statistical parametric mapping (SPM). Nat. Protoc. 10 (2), 293-304.

Li, C.T., Lin, C.P., Chou, K.H., Chen, I.Y., Hsieh, J.C., Wu, C.L., Lin, W.C., Su, T.P., 2010. Structural and cognitive deficits in remitting and non-remitting recurrent depression: a voxel-based morphometric study. Neuroimage 50 (1), 347-356.

Liu, W., Mao, Y., Wei, D., Yang, J., Du, X., Xie, P., Qiu, J., 2016. Structural asymmetry of dorsolateral prefrontal cortex correlates with depressive symptoms: evidence from healthy individuals and patients with major depressive disorder. Neurosci. Bull. 32 (3), 217-226.

Onitsuka, T., Shenton, M.E., Salisbury, D.F., Dickey, C.C., Kasai, K., Toner, S.K. Frumin, M., Kikinis, R., Jolesz, F.A., McCarley, R.W., 2004. Middle and inferior temporal gyrus gray matter volume abnormalities in chronic schizophrenia: an MRI study. Am. J. Psychiatry 161 (9), 1603-1611.

Peng, J., Liu, J., Nie, B., Li, Y., Shan, B., Wang, G., Li, K., 2011. Cerebral and cerebellar gray matter reduction in first-episode patients with major depressive disorder: a voxel-based morphometry study. Eur. J. Radiol. 80 (2), 395-399.

Plewnia, C., Pasqualetti, P., Grosse, S., Schlipf, S., Wasserka, B., Zwissler, B. Fallgatter, A., 2014. Treatment of major depression with bilateral theta burst stimulation: a randomized controlled pilot trial. J. Affect. Disord. 156, 219-223.

Kumar, A., Bilker, W., Lavretsky, H., Gottlieb, G., 2000. Volumetric asymmetries in lateonset mood disorders: an attenuation of frontal asymmetry with depression severity. Psychiatry Res. Neuroimaging 100, 41-47. https://doi.org/10.1016/S0925-4927 (00)00067-6.

Schmaal, L., Hibar, D.P., Samann, P.G., Hall, G.B., Baune, B.T., Jahanshad, N., Cheung, J. W., van Erp, T.G.M., Bos, D., Ikram, M.A., Vernooij, M.W., Niessen, W.J., Tiemeier, H., Hofman, A., Wittfeld, K., Grabe, H.J., Janowitz, D., Bulow, R. Selonke, M., Volzke, H., Grotegerd, D., Dannlowski, U., Arolt, V., Opel, N., Heindel, W., Kugel, H., Hoehn, D., Czisch, M., Couvy-Duchesne, B., Renteria, M.E., Strike, L.T., Wright, M.J., Mills, N.T., de Zubicaray, G.I., McMahon, K.L., Medland, S. E., Martin, N.G., Gillespie, N.A., Goya-Maldonado, R., Gruber, O., Kramer, B., Hatton, S.N., Lagopoulos, J., Hickie, I.B., Frodl, T., Carballedo, A., Frey, E.M., van Velzen, L.S., Penninx, B., van Tol, M.J., van der Wee, N.J., Davey, C.G., Harrison, B. J., Mwangi, B., Cao, B., Soares, J.C., Veer, I.M., Walter, H., Schoepf, D., Zurowski, B., Konrad, C., Schramm, E., Normann, C., Schnell, K., Sacchet, M.D., Gotlib, I.H., MacQueen, G.M., Godlewska, B.R., Nickson, T., McIntosh, A.M., Papmeyer, M., Whalley, H.C., Hall, J., Sussmann, J.E., Li, M., Walter, M., Aftanas, L., Brack, I., Bokhan, N.A., Thompson, P.M., Veltman, D.J., 2017a. Cortical abnormalities in adults and adolescents with major depression based on brain scans from 20 cohorts worldwide in the ENIGMA major depressive disorder working group. Mol. Psychiatry 22 (6), 900-909.

Martin, D.M., McClintock, S.M., Forster, J., Loo, C.K., 2016. Does therapeutic repetitive transcranial magnetic stimulation cause cognitive enhancing effects in patients with neuropsychiatric conditions? a systematic review and meta-analysis of randomised controlled trials. Neuropsychol. Rev. 26, 295-309. https://doi.org/10.1007/s11065016-9325-1.

Mohn, C., Rund, B.R., 2016. Neurocognitive profile in major depressive disorders: relationship to symptom level and subjective memory complaints. BMC Psychiatry 16. https://doi.org/10.1186/s12888-016-0815-8.

Park, Y., Jung, W., Kim, S., Jeon, H., Lee, S.-.H., 2019. Frontal alpha asymmetry correlates with suicidal behavior in major depressive disorder. Clin. Psychopharmacol. Neurosci. 17, 377-387. https://doi.org/10.9758/ cpn. 2019.17.3.377.

Schmaal, L., Hibar, D.P., Sämann, P.G., Hall, G.B., Baune, B.T., Jahanshad, N., Cheung, J. W., van Erp, T.G.M., Bos, D., Ikram, M.A., Vernooij, M.W., Niessen, W.J., Tiemeier, H., Hofman, A., Wittfeld, K., Grabe, H.J., Janowitz, D., Bülow, R., Selonke, M., Völzke, H., Grotegerd, D., Dannlowski, U., Arolt, V., Opel, N., Heindel, W., Kugel, H., Hoehn, D., Czisch, M., Couvy-Duchesne, B., Rentería, M.E., Strike, L.T., Wright, M.J., Mills, N.T., de Zubicaray, G.I., McMahon, K.L., Medland, S. E., Martin, N.G., Gillespie, N.A., Goya-Maldonado, R., Gruber, O., Krämer, B., Hatton, S.N., Lagopoulos, J., Hickie, I.B., Frodl, T., Carballedo, A., Frey, E.M., van Velzen, L.S., Penninx, B.W.J.H., van Tol, M.-.J., van der Wee, N.J., Davey, C.G., Harrison, B.J., Mwangi, B., Cao, B., Soares, J.C., Veer, I.M., Walter, H., Schoepf, D., Zurowski, B., Konrad, C., Schramm, E., Normann, C., Schnell, K., Sacchet, M.D., Gotlib, I.H., MacQueen, G.M., Godlewska, B.R., Nickson, T., McIntosh, A.M., Papmeyer, M., Whalley, H.C., Hall, J., Sussmann, J.E., Li, M., Walter, M., Aftanas, L., Brack, I., Bokhan, N.A., Thompson, P.M., Veltman, D.J., 2017b. Cortical 
abnormalities in adults and adolescents with major depression based on brain scans from 20 cohorts worldwide in the ENIGMA major depressive disorder working group. Mol. Psychiatry 22, 900-909. https://doi.org/10.1038/mp.2016.60.

Suh, J.S., Minuzzi, L., Raamana, P.R., Davis, A., Hall, G.B., Harris, J., Hassel, S. Zamyadi, M., Arnott, S.R., Alders, G.L., Sassi, R.B., Milev, R., Lam, R.W.,

MacQueen, G.M., Strother, S.C., Kennedy, S.H., Frey, B.N., 2020. An investigation of cortical thickness and antidepressant response in major depressive disorder: a CANBIND study report. NeuroImage Clin 25, 102178. https://doi.org/10.1016/j. nicl.2020.102178. van Tol, M.-.J., Li, M., Metzger, C.D., Hailla, N., Horn, D.I., Li, W., Heinze, H.J., Bogerts, B., Steiner, J., He, H., Walter, M., 2014. Local cortical thinning links to resting-state disconnectivity in major depressive disorder. Psychol. Med. 44, 2053-2065. https://doi.org/10.1017/S0033291713002742.

Ye, M., Qing, P., Zhang, K., Liu, G., 2016. Altered network efficiency in major depressive disorder. BMC Psychiatry 16, 450. https://doi.org/10.1186/s12888-016-1053-9.

Zuo, Z., Ran, S., Wang, Y., Li, C., Han, Q., Tang, Q., Qu, W., Li, H., 2019. Asymmetry in cortical thickness and subcortical volume in treatment-naive major depressive disorder. Neuroimage Clin. 21, 101614. 